\title{
Antimaláricos em Osteoartrite
}

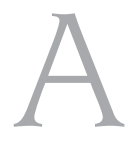

pesar de ser a mais freqüente artropatia crônica inflamatória, a osteoartrite $(\mathrm{OA})$ ainda carece de tratamento eficaz, seja para minimizar sintomas, seja para alterar dano estrutural. A última publicação sobre guias de conduta da Comissão de Osteoartrite da Sociedade Brasileira de Reumatologia ${ }^{(1)}$ data de 2002, e uma atualização será publicada proximamente. Com relação à $\mathrm{OA}$ de quadril e joelhos, os guidelines da Sociedade Internacional de Osteoartrite (OARSI) ${ }^{(2)}$ foram publicados recentemente e balizaram a orientação brasileira.

Neste número da Revista Brasileira de Reumatologia, Bonfante e cols. publicam os resultados de um estudo sobre a eficácia da hidroxicloroquina administrada a pacientes com OA de joelhos, comparando a placebo ${ }^{(3)}$. O estudo tem limitações quanto ao tamanho da amostra e o relativo pequeno tempo de observação. Entretanto, tem o mérito de representar um estudo controlado sobre o uso de um grupo de medicamentos, os antimaláricos, que a prática diária reumatológica brasileira entende como útil para tratar OA. Esse tipo de conduta, considerada baseada na opinião de especialistas, tem a fragilidade de não se pautar em estudos controlados. Por outro lado, tem a força da experiência clínica, no tratamento de uma condição que ainda carece de terapias efetivas. Dessa forma, tentativas empíricas são realizadas, no intuito de oferecer alternativas de tratamento, sem implicar riscos significativos de eventos adversos.

Entendendo que a OA não é necessariamente uma doença de curso inexorável, na qual todos os pacientes seguirão sempre piorando, a despeito da terapêutica instituída, esse empirismo tem seu valor. Entretanto, a realização de estudos como o de Bonfante traz os antimaláricos para a confrontação com a evidência científica, prática imprescindível na busca de avanços em medicina.

\section{REFERÊNCIAS}

1. Coimbra IB, Hirose-Pastor E, Greve JMD'A, et al. Consenso Brasileiro para o Tratamento da Osteoartrite. Rev Bras Reumatol 42(6):371-4, 2002.

2. Zhang W, Moskowitz RW, Nuki G, et al. OARSI recommendations for the management of hip and knee osteoarthritis, Part II: OARSI
Os resultados obtidos não revelaram diferença entre o grupo que recebeu hidroxicloroquina ou placebo, para todos os parâmetros avaliados, que consideraram dor e limitação funcional. Seguramente se pode criticar aspectos do tamanho reduzido da amostra e o tempo de observação, bem como a dificuldade que a melhora com placebo representa para atingir diferença estatisticamente significante. Considerando o aspecto multifatorial da dor na OA e que seus mecanismos são obscuros, não admira que praticamente todos os estudos nessa patologia sofram esse viés. A busca por parâmetros que possam refletir danos estruturais na OA e índices de lesão reprodutíveis e quantificáveis com variáveis com distribuição normal é uma "necessidade não atendida" para que se possam avaliar adequadamente intervenções em OA.

Bonfante e cols. citam apenas um artigo específico avaliando o efeito de antimaláricos em $\mathrm{OA}$, pelo menos em literatura de língua inglesa. Como dito anteriormente, a experiência brasileira, não documentada, acredita no benefício dessa medicação no tratamento da $\mathrm{OA}$, particularmente na sua forma nodal, erosiva, em mãos. Embora reconhecendo a importância do artigo de Bonfante e cols., parece-nos razoável que um grande mérito dessa publicação deva ser a motivação para que estudos com maior casuística, por tempo prolongado, avaliando parâmetros de dano estrutural (ainda que esses sejam frágeis como a radiologia), se possível de forma multicêntrica sejam realizados para atender uma necessidade que a reumatologia brasileira pode preencher.

Os Editores

evidence-based, expert consensus guidelines. Osteoarthritis Cartilage 16:137-62, 2008.

3. Bonfante HL, Machado LG, Capp AA, et al. Avaliação do uso da hidroxicloroquina no tratamento da osteoartrite sintomática de joelhos. Rev Bras Reumatol 48(4):208-12,2008 